\title{
VEINTITRÉS AÑOS DE RECURSO DE AMPARO
}

\author{
ÁNGELA FIGUERUELO BURRIEZA \\ ProfesoraTitular de Derecho Constitucional \\ Universidad de Salamanca
}




\title{
VEINTITRÉS AÑOS DE RECURSO DE AMPARO
}

\author{
POR \\ ÁNGELA FIGUERUELO BURRIEZA \\ Profesora Titular de Derecho Constitucional \\ Universidad de Salamanca
}

1. La garantía constitucional del recurso de amparo es un instituto medular de la actual organización jurisdiccional del Estado español. Su análisis debe ser planteado a partir de su entendimiento como un recurso extraordinario de protección de los derechos y libertades fundamentales reconocidos en los artículos 14 al 29 y en el párrafo $2 .^{\circ}$ del artículo 30 de la Constitución Española frente a las violaciones cometidas por actos de los poderes públicos. Su resolución se efectúa en la instancia constitucional.

Para poder entender el establecimiento de una garantía jurisdiccional en el marco de la justicia constitucional, entendida en sentido formal, es necesario conocer los problemas a los que debió hacer frente el constituyente de 1978. La idea de libertad, después de la larga etapa de la dictadura franquista, había tomado carta de naturaleza como indiscutible premisa a tener en cuenta a la hora de la reconstrucción constitucional. En ese momento histórico las libertades individuales se reconocen como justificación y fuente de la soberanía del Estado, antes que como sus límites necesarios y congénitos; son la fuerza motriz sin la cual el Estado Democrático no puede lograr su desarrollo. Así pues, libertades individuales y soberanía popular aparecen afirmadas conjuntamente como expresiones de una misma concepción política que encuentran su fundamentación jurídica en la Constitución, siendo dos aspectos complementarios e inescindibles de la democracia traducida en ordenamiento positivo. Por todo ello en los 
sistemas democráticos de gobierno las libertades políticas individuales serán necesarias no sólo como reconocimiento de la dignidad de la persona sino también como medio de hacer efectiva y fecunda la vida política de la comunidad y para conseguir que todos los ciudadanos puedan libremente contribuir a la formación y renovación constante de aquella voluntad común que en la democracia es el único título de legitimación de la autoridad. Las libertades individuales se presentan como la primordial exigencia del poder público porque de ellas requiere la democracia para su supervivencia.

Los derechos de libertad son los garantes de la participación de los particulares en la vida política de la comunidad. Por ello, desde el punto de vista de su eficacia práctica lo más importante no es su solemne proclamación en los textos constitucionales sino el establecimiento de garantías específicas para lograr su vigencia efectiva (KELSEN).

El reconocimiento amplio que se hizo en la Constitución de 1978 de los derechos y libertades fundamentales implica el compromiso del Estado de no servirse de sus poderes para suprimirlos o para restringirlos. Por todo ello, cuando hablamos de defensa de los derechos de libertad significa ante todo hablar de defensa frente a los poderes públicos, sin que ello permita olvidar que en el momento actual de la globalización económica y mediática cada vez quedan menos espacios para la libertad de los ciudadanos (DE VEGA GARCíA) y, sus derechos fundamentales con frecuencia se verán perturbados por los grandes poderes privados que ocupan una situación de privilegio, incluso frente al propio Estado, que cada vez es menos soberano (RUIPÉREZ).

Desde esta perspectiva analizamos el recurso de amparo entendido como el último estadio de las garantías jurisdiccionales que en nuestra Constitución se consagran para lograr la vigencia efectiva de los derechos fundamentales. Así aparece reconocido en los artículos $53.1 ; 161.1 \mathrm{~b})$ y $162.1 \mathrm{~b}$ ) de la Constitución y desarrollado en los artículos 41 al 58 de la LOTC.

2. Buscar antecedentes históricos (GARCÍA RUIZ) en la figura del recurso de amparo obliga a repasar la historia de nuestro constitucionalismo (TOMÁS VILLARROYA, SOLÉ TURA y AJA). En el clima sociocultural de la España del siglo XIX no pudo arraigar un verdadero sentimiento constitucional, ni tampoco en las numerosas constituciones existentes aparecen instrumentos que puedan ser considerados como garantías especificas para la protección de los escasos derechos que se recogían en esos textos nominales o semánticos. Ni siquiera en la Constitución de 1869 se estableció un derecho a la tutela juris- 
diccional como medio de protección judicial de los derechos consagrados.

Es en el texto constitucional de la Il República, en la Constitución Española de 1931, cuando nos encontramos con el primer antecedente directo de nuestro actual recurso de amparo. En los artículos $105 \mathrm{y}$ 121 de dicha norma se creó un Tribunal de Garantías Constitucionales, al cual, entre otras funciones se le encomendó el conocimiento del recurso de amparo de garantías individuales (RUIZ LAPEÑA, GARCÍA RUIZ). Conviene destacar lo novedoso de esta garantía de naturaleza jurisdiccional porque en el desarrollo del concepto de justicia constitucional imperante en Europa en esos momentos se fijaba la atención en el control de constitucionalidad de las normas (KELSEN). Como no se llegaron a crear los Tribunales de Urgencia que debían conocer en primera instancia del recurso y como consecuencia de haber sufrido una tremenda reducción el objeto de dicho recurso en su desarrollo legislativo ordinario, el funcionamiento de esta institución no obedeció a la idea inicial quedando prácticamente relegado a la resolución de recursos planteados frente a multas impuestas por motivos de orden público (BASSOLS COMA). Aunque no restamos importancia a una jurisprudencia creada "ex novo" en unas condiciones socio-politicas nada propicias, es conveniente destacar que al acercarse al conocimiento del actual recurso de amparo debemos prescindir de la ayuda que en estos casos suelen prestar los precedentes históricos más inmediatos.

Tampoco el recurso a la ayuda que pueda prestar la «mens legislatoris" nos es útil en este caso, pues, la aprobación sin discusiones en el proceso constituyente de los artículos 53.2, 161 y 162 de la C.E. y la ausencia de discusiones en la aprobación de la LOTC como consecuencia del consenso entre los distintos grupos políticos, elimina un centro referencial importante a la hora de analizar este tema. No podemos olvidar el marco del derecho comparado y sus influencias respecto al caso español. En este ámbito y debido al "efecto mimético» que tantas instituciones del constitucionalismo alemán ejercieron sobre el constituyente de 1978, la "Verfassungsbeschwerde" o "recurso de queja» del derecho germano es el modelo por excelencia seguido en el supuesto español (VON MÜNCH). Incluso, conviene reconocer ciertas influencias de la Beschwerde suiza y austriaca. El caso mexicano, a pesar de la identidad en la denominación (REYES) ha estado durante mucho tiempo separado conceptual e institucionalmente de nuestro modelo. El juicio de amparo mexicano es de una gran amplitud competencial (FIX ZAMUDIO) pero actualmente se encuentra en fase de reforma siendo el recurso de amparo español una de las 
instituciones que están siendo tenidas en cuenta de cara a las modificaciones "pro futuro".

Para conocer las razones que justifican la constitucionalización del recurso de amparo es obligado reflexionar con carácter general para situar en su contexto todo el problema. El modelo de justicia constitucional adoptado en la CE de 1978 sigue las pautas del modelo concentrado o austriaco. En este modelo el recurso de amparo no tiene un sencillo acomodo porque supone la asunción por el juez constitucional de un papel distinto al de "legislador negativo" en el cual se realiza un juicio abstracto de la constitucionalidad de las normas. En cambio, en el recurso de amparo, el juez constitucional se convierte en juez del caso concreto resolviendo la conformidad o no de un acto de relevancia jurídica con los postulados constitucionales. Así, la doctrina sostiene que el recurso de amparo no pertenece a la esencia del modelo concentrado de justicia constitucional. Pero la efectividad de la tutela de los derechos lograda a través de esta garantía ha provocado su extensión a distintos países europeos e iberoamericanos a la vez que se ha elaborado el concepto de justicia constitucional como verdadera jurisdicción de las libertades (CAPPELLETTI).

En el ámbito de la justicia constitucional como jurisdicción de la libertad conviene entender el recurso de amparo como garantía de los derechos fundamentales reconocidos con gran amplitud como reacción a la situación histórica precedente. La doctrina insiste en que no se debe olvidar la configuración del Poder Judicial en España en 1978 y la total ausencia de tradición judicial española se enmarca en el más puro jacobinismo puesto que el juez era considerado un simple aplicador de la ley. La aplicación directa en los procedimientos judiciales de los derechos reconocidos en la Constitución por parte de los jueces en el momento de la transición política era algo totalmente extraño a su formación secular. Se había generalizado la idea de que los derechos fundamentales eran normas programáticas que requerian la "interpositio legislatoris" para adquirir plena eficacia y poder ser alegados ante los tribunales de justicia. Ejemplos de esta forma de entender los derechos se pueden encontrar en las resoluciones de los más Altos Tribunales del país hasta 1981 o 1982 (BUSTOS GISBERT).

3. Los debates en sede constituyente fueron escasos pero sí pusieron de relieve al tramitarse las normas relativas al recurso de amparo la ausencia de unanimidad sobre la conveniencia de introducir esta institución así como respecto a su instrumentación concreta. Manifestaron sus dudas sobre la institución los senadores Martín Retortillo, Azcárate y Angulo Montes. Sus reservas afectaban tanto al 
aspecto teórico como al práctico de la precipitada garantía de los derechos fundamentales. Se aducía que, desde un punto de vista teórico, era innecesario el recurso ante el Tribunal Constitucional porque se había reconocido un recurso de amparo "ordinario" ante los jueces y tribunales a tenor del art. $\mathbf{5 3 . 2}$ de la C.E. Si al Poder Judicial se le encomendaba la protección de los Derechos Fundamentales no tenía sentido que se introdujera otro tribunal, ajeno a la estructura del Poder Judicial, para realizar una misma función, porque, sin duda, esa situación generaría conflictos entre ambas instancias. De cara a su funcionamiento en la práctica se pensaba que el recurso de amparo produciría dos tipos de disfuncionalidades importantes: la creación de una nueva instancia superior al Poder Judicial (supercasación) y el bloqueo del funcionamiento del Tribunal Constitucional porque el aumento de los recursos de amparo restaría fuerzas al Alto Tribunal para atender otras funciones constitucionales cuya resolución le había sido también encomendada.

Por todos estos recelos en el artículo 53.2 se estableció expresamente:

"Cualquier ciudadano podrá recabar la tutela de las libertades y derechos reconocidos en el artículo 14 y la Sección Primera del Capítulo Segundo ante los Tribunales ordinarios por un procedimiento basado en los principios de preferencia y sumariedad y, en su caso, a través del recurso de amparo ante el Tribunal Constitucional. Este último recurso será aplicable a la objeción de conciencia reconocida en el artículo 30 ".

Literalmente este precepto expresa que solo pueden ser objeto de amparo un número reducido de derechos (los contenidos en los artículos 14 al $30,2 .^{\circ}$ de la C.E.). Objeto que reitera el artículo 41.1 de la L.O.T.C. Además no se reconocía la posibilidad de recurrir decisiones judiciales que supusieran una excesiva protección de los derechos -el llamado contraamparo - (REVENGA) ni se permitía el amparo contra leyes (BORRAJO, FIGUERUELO) y sólo se preveía la posibilidad de recurrir actos de los poderes públicos y no de los particulares (BILBAO, DE VEGA, FIGUERUELO): la práctica forense del Tribunal Constitucional y la abundancia de trabajos doctrinales sobre ella nos ponen de manifiesto que las limitaciones en el objeto procesal y en el sujeto pasivo del recurso de amparo no han servido para cumplir los objetivos en un principio perseguidos. (JIMÉNEZ CAMPO).

También del artículo 53.2 se deduce la existencia de un recurso preferente y sumario (FRIGINAL) ante los Tribunales Ordinarios encargados en primer lugar, de velar por la eficacia de los derechos funda- 
mentales. Sería el urecurso de amparo ordinario" frente al "recurso de amparo constitucional» que se sustenta ante el Tribunal Constitucional. La expresión "en su caso" que recoge el artículo 53 de la CE unida a la fórmula "en los casos y formas que la ley establezca" del artículo 161.1 b de la $\mathrm{CE}$, de muy distinta interpretación doctrinal, dieron lugar a que la LOTC diseñara un recurso de amparo constitucional subsidiario, siguiendo el modelo del recurso de queja alemán, respecto del amparo preferente y sumario ante la judicatura ordinaria, y sobre el cual se realizaba un mandato al legislador en el art. 53.2 de la CE. En función de ello no cabe el recurso constitucional directo ante el Tribunal Constitucional excepto en el supuesto previsto en el artículo 42 de la LOTC: cuando los derechos objeto de protección en amparo habian sido violados por actos sin valor de ley del Parlamento o de las Asambleas Legislativas de las Comunidades Autónomas, o de cualquiera de sus órganos. El plazo para recurrir será de tres meses a partir del momento en que de acuerdo a las correspondientes normas internas sean firmes.

En el supuesto de que los poderes causantes de la violación de un derecho fundamental amparable fuese el poder ejecutivo (art. 43 de la LOTC) sería requisito imprescindible alegar dicha violación ante los tribunales ordinarios y agotar todos los recursos posibles antes de acudir al Tribunal Constitucional. Así las cosas, el juez ordinario sería el juez natural de los derechos quedando el recurso de amparo constitucional como un recurso procesal extraordinario y excepcional para la protección de los derechos cuando estos no hubieren obtenido la oportuna protección por los jueces y magistrados.

A pesar del marcado acento esta subsidiariedad no ha funcionado como un verdadero filtro para evitar la excesiva proliferación de recursos ante el Alto Tribunal. Incluso conviene destacar que, en el ánimo de diferenciar las funciones del amparo ordinario y del constitucional en el campo de la protección de derechos, se procedió a separar la labor del Tribunal Constitucional como juez de la constitucionalidad y la del juez ordinario como juez de la legalidad (RUBIO LLORENTE). En esta tarea de protección de derechos la supremacía como órgano recae en el TC tal y como reconoce el artículo 123.1 de la CE y el juicio efectuado en ambas instancias es diferente: al juez constitucional no le corresponde examinar los hechos que dieron lugar al proceso en el que se produjo la lesión presunta al derecho (art. 44.1 b de la LOTC) ni realizar consideraciones sobre la interpretación de las leyes, únicamente debe examinar si el juez ordinario respetó en su decisión el contenido del derecho. EITC no puede revisar la interpretación de la ley. Si esto se aprecia correctamente se evi- 
tan los conflictos entre el Poder Judicial y el intérprete supremo de la Constitución porque funcionalmente elTC no podría incidir en la tarea que el art. 117.3 de la CE encomienda a la judicatura ordinaria.

Se quiso evitar, aunque no se pudo, la avalancha de recursos de amparo mediante la regulación de los motivos de inadmisibilidad de tal forma que el Tribunal Constitucional pudiera hacer una importante selección de los supuestos que entraría a conocer. Las causas de inadmisión contenidas en el art. $50.1 \mathrm{c}$ y d de la LOTC configuraban un sistema de inadmisión que resultaba excesivamente largo y complejo. Por ello, la reforma efectuada por la LO 6/88 facilitó que fueran las secciones delTC las que mediante providencia denegaran la admisión. También se limitó la posibilidad de recurso contra tales decisiones (RUBIO, GARCÍA ROCA).

En conclusión, de la parca regulación del recurso de amparo en la CE y de su desarrollo algo más amplio efectuado en la LOTC podemos resaltar que la institución del amparo en cuanto garantía constitucional de los derechos fundamentales es un auténtico proceso dirigido a impugnar (salvo en el caso del art. 42 de la LOTC) sentencias judiciales. Como todo recurso, no es la continuación del proceso principal, sino un proceso autónomo e independiente, con un régimen, juridico peculiar (RUBIO LLORENTE). Es además un recurso extraordinario y excepcional: extraordinario en cuanto que el órgano jurisdiccional no puede pronunciarse sobre la totalidad de la cuestión litigiosa, sino solo sobre aquellos sectores que sean correspondientes con la índole del recurso. Y excepcional porque como el recurso de revisión y el de audiencia al rebelde, el de amparo no suspende la firmeza de las sentencias contra las que se dirige. Es además un recurso en grado supremo porque la decisión del TC como órgano de cierre del sistema, encargado de velar por la supremacía de la Constitución, no puede ser anulada por ningún otro órgano.

4. El objeto protegido por el recurso de amparo aparece fijado en el art. 53.2 de la CE y en el art. 41.1 de la LOTC. De ambos textos normativos se deduce la delimitación del objeto en forma taxativa: se protegen los derechos y libertades reconocidos en los artículos 14 al 30.2 de la C.E. También el TC aplica con frecuencia la norma que limita el objeto del amparo, ya sea para inadmitir o desestimar recursos cuya pretensión esté fundada en derechos diferentes a los consagrados en los precitados artículos. La literalidad de los preceptos constitucionales y legales otorgan seguridad a la hora de conocer si un derecho se encuentra o no en la lista objeto de protección. Pero, a pesar de reiterar el carácter restringido del objeto del recurso de amparo y 
de la frecuente inadmisión de recursos por no fundamentarse en algún derecho fundamental objeto de protección (CASCAJO, OSUNA PATIÑO) el Alto Tribunal mantiene una conducta de moderada flexibilidad en la interpretación de estos preceptos y como consecuencia se ha extendido el ámbito del recurso de amparo a derechos y libertades que en el más puro rigor exegético se encontrarían fuera del mismo.

Esta extensión del objeto del recurso de amparo se ha llevado a cabo por dos vías: mediante la incorporación en el contenido de un derecho susceptible de amparo de otro derecho en principio ajeno al mismo y, por medio de la aplicación instrumental de un derecho susceptible de amparo, especialmente del principio de igualdad ante la ley (art. 14 de la CE) o del derecho a la tutela judicial efectiva (art. 24 de la $C E)$.

A tenor de lo que hemos señalado las normas y la jurisprudencia delTC ponen de manifiesto la insuficiencia del sistema de «numerus clausus" como parámetro de delimitación del objeto protegido por el recurso de amparo dadas las especiales características de los derechos fundamentales (BÖCKENFÖRDE). El rango constitucional y la vinculación general que deriva de su jerarquía normativa acarrea importantes consecuencias jurídicas.

El carácter abierto y expansivo de los derechos fundamentales y su consagración en cláusulas generales amplia notablemente las fronteras del recurso de amparo porque, a partir de los principios constitucionales, pueden deducirse dérechos no expresamente mencionados en las Constituciones o incluirse dentro del ámbito de dicha garantía otros derechos que, en principio, estarían excluidos de la misma.

Desde una perspectiva jurídico constitucional el recurso de amparo ha cumplido una doble función con importantes consecuencias. La función subjetiva sirve para realizar una tutela procesal cualificada de los derechos fundamentales frente a violaciones cometidas por actos de los poderes públicos (remedio extraordinario de protección de derechos). Pero, en su dimensión objetiva, el recurso de amparo permite la creación de un "corpus jurisprudencial" en torno al contenido concreto de los derechos fundamentales La relevancia de esta función permite la centralización de la jurisprudencia de los derechos en una única instancia cuyas decisiones vinculan a los tribunales inferiores. También destaca la labor de adaptación de los contenidos de los derechos a los cambios sociales. Ahora bien, consideramos que la dimensión objetiva de los derechos fundamentales sólo de forma indi- 
recta debe ser objeto de protección por el TC, en cuanto efecto agregado a la protección subjetiva de los derechos invocados en los diferentes casos particulares sometidos a su resolución.

En el marco teórico previamente expuesto conviene resaltar que la Jurisprudencia delTC español ha transformado el objeto del amparo en pro de un mejor cumplimiento de las dos facetas subjetiva y objetiva de la tutela que le ha sido encomendada. Se ha ampliado el contenido de los derechos fundamentales hasta la inclusión de supuestos no expresamente previstos por el constituyente, como por ejemplo los llamados derechos de configuración legal (básicamente los arts. 23 y 28 de la CE), el efecto amplificador del art. 14 que ha permitido la inclusión de nuevos derechos como consecuencia de las eventuales desigualdades producidas en su aplicación judicial y la inclusión de derechos por conexión con algunos de los contenidos en la Sección 1.a, como por ejemplo, el derecho a la determinación de la filiación como consecuencia de la actuación conjunta de los artículos 14 y 24 en relación con el artículo 39 de la CE.

En términos muy amplios y generales reconoció el constituyente las garantías del proceso en el art. 24 de nuestra norma suprema. Esa vaguedad le ha permitido llevar a cabo al Tribunal Constitucional una interpretación extensiva de las mismas tanto en el caso del derecho a la tutela judicial efectiva (art. 24.1) como el de los derechos que entran en juego en el seno del proceso (art. 24.2). Las críticas efectuadas a este derecho recaen sobre su objeto y contenido porque la Constitución establece que la finalidad del derecho es obtener la tutela efectiva en el ejercicio de los derechos e intereses legítimos. Con ello no aparece de forma clara la delimitación del derecho de acceso a los Tribunales o derecho a la Jurisdicción puesto que, el derecho reconocido, se relaciona con el requisito de la legitimación propio de la pretensión y no del derecho de acción e incluso llega a vincularse con el propio derecho material. También el requisito de la efectividad aplicado a la tutela y no al derecho debe entenderse referido a éste que es al que debe calificar y así queda reflejado en otros artículos del propio texto constitucional que aluden a gratuidad de la justicia, prohibición de dilaciones indebidas... A pesar de las críticas doctrinales la indeterminación de la norma constitucional (art. 24.1 de la CE) contenía un amplio espectro de posibilidades de actuación concreta que fueron activadas por elTC a través de la vía del recurso de amparo y convirtieron el derecho a la tutela judicial efectiva, nervio del Estado de Derecho, en el derecho estrella del ordenamiento jurídico español (DÍEZ-PICAZO). Es el derecho que con más frecuencia se invoca ante el TC pues recoge los enunciados que constituyen las garantías bási- 
cas de la administración de justicia elevadas al rango de derechos subjetivos tutelables en amparo ante elTC. Este órgano constitucional ha realizado interpretaciones muy aperturistas y generosas a la hora de definir el contenido esencial de los derechos del art. 24. Esa jurisprudencia, con efectos "erga omnes", imprescindible para entender el significado actual de dicho precepto, de nuestra vigente legislación procesal y de las modificaciones últimamente sufridas, así como de su aplicación por los Tribunales de Justicia (GONZÁLEZ PÉREZ).

Brevemente resumido el contenido esencial del derecho a la tutela judicial efectiva, que en el caso de ser perturbado puede fundamentar una demanda de amparo, sería el siguiente:

- Derecho de acceso a la jurisdicción.

- Derecho a que el proceso se desarrolle con todas las garantias y se obtenga una resolución judicial sobre el fondo del asunto siempre que se cumplan los requisitos formales para ello.

- Aunque no incluye el derecho a obtener una sentencia favorable si se exige una resolución fundada en derecho y que recaiga sobre el fondo del asunto.

- Esa resolución debe ser motivada conforme a lo exigido en el art. 120.3 de la C.E.

- Se prohíbe la incongruencia por sumisión de pronunciamiento.

- Forma parte de su contenido el derecho a los recursos y a la doble instancia en la vía penal.

- Se exige el derecho a la ejecución de las sentencias y el derecho a la invariabilidad e intangibilidad de las resoluciones judiciales y a la tutela cautelar.

El desarrollo de este precepto constitucional gracias al recurso de amparo es uno de los más avanzados y complejos en el marco del derecho constitucional comparado. Las críticas efectuadas a las combinaciones del párrafo $1 .^{\circ} \mathrm{del}$ art. 24 con las particularidades propias del proceso penal reguladas en el párrafo $2 .^{\circ}$ las sortea el Alto Tribunal señalando que las garantías del párrafo $2 .^{\circ}$, aunque se dirijan principalmente al proceso penal, afectan a todo tipo de procesos y sin dichas garantías no hay tutela judicial efectiva. De ahí la implicación de ambos apartados, genérico el primero y más enfocado hacia el proceso penal el segundo. Esta interpretación amplia y extensiva, formulada por elTC, quizás de forma inevitable, ha provocado que la mayor 
parte de las resoluciones de los jueces y tribunales ordinarios sean recurribles en amparo, convirtiendo en objeto del recurso no solo los errores "in iudicando" sino también cualquier error "in procedendo". Y si esto ha sucedido en relación al grupo de derechos objeto de protección en amparo que aparecía tasado en el marco constitucional y legal algo parecido ha sucedido con el sujeto pasivo, objeto del recurso de amparo, causante de la violación del derecho fundamental: tanto de la CE como de la LOTC en su temor literal se deduce que solo cabe el amparo frente a violaciones causadas por actos de los poderes públicos. Si observamos la jurisprudencia constitucional apreciamos abundantes resoluciones en las cuales en virtud de una interpretación extensiva los derechos y libertades vinculan inmediatamente a los poderes públicos y de forma mediata, a través de la ley y de las cláusulas generales también a los particulares. El Alto Tribunal siguiendo esta doctrina ha dado luz verde a la teoría de la "Drittwirkung der Grundrechte" o eficacia de los derechos fundamentales frente a terceros particulares o poderes privados (QUADRA-SALCEDO, PABÓN DE ACUÑA, VARELA) aunque para hacer posible el acceso al recurso de amparo de las quejas dirigidas contra el comportamiento ilegal $y$ violatorio de los derechos fundamentales por los particulares se haya tenido que forzar en alguna medida la letra del artículo 44.1.b de la LOTC, entendiendo que son directamente imputables a los jueces las violaciones que resultan del hecho de que estos hayan aplicado leyes inconstitucionales o hayan aplicado de un modo inconstitucionalmente incorrecto normas que en sí mismas no son contrarias a la Constitución, al dirimir litigios entre particulares. Esta interpretación ha ampliado notablemente el cauce angosto que ofrecían la CE y la LOTC para protegerlos frente a su violación por los órganos del Poder Judicial (POYAL COSTA, PALOMEQUE, EMBID IRUJO, AGUIAR).

5. De la lectura de la CE se desprende el carácter marcadamente subjetivo en la regulación del recurso de amparo. El artículo 162.1.b legitima para su interposición a «toda persona natural o jurídica que invoque un interés legítimo, así como al Defensor del Pueblo $y$ al Ministerio Fiscal». Vemos como la legitimación activa de estos últimos no desconfigura el carácter personalista del recurso en cuestión porque en ambos casos la legitimación otorgada va en consonancia con los fines que se les atribuye a dichas instituciones en los artículos 124 y 54 de la $C E$, respectivamente. El carácter subjetivo que inspira al recurso de amparo determina la naturaleza jurídica de las pretensiones exigibles ante el TC y da satisfacción al requisito de la legitimación impuesto en la $\mathrm{CE}$, norma que para entablarlo exige una legitimación personal y específica que implica una relación subjetiva entre 
el actor y el objeto del recurso. El actor debe ser titular de un interés legítimo en la resolución del proceso (GONZÁLEZTREVIJANO). Dicha legitimación no hubiera planteado problemas si el concepto y el significado de interés legítimo hubiera estado perfilado de forma clara en la doctrina y en la jurisprudencia. Pero esto no ha sido así. El interés legítimo es una categoría más amplia que la de derecho subjetivo pero no puede confundirse con la acción popular entendida lisa y llanamente como el interés por la legalidad (CORDÓN MORENO). Es necesario acudir a la jurisprudencia delTC que tampoco nos ha proporcionado un concepto específico de esa noción en el marco de la propia Constitución. Únicamente ha precisado que la expresión «interés legítimo" utilizada por la $C E$, aunque sea un concepto diferente y más amplio que el de "interés directo" ha de entenderse referida a un interés en sentido propio, cualificado o específico. No se puede confundir con el interés genérico en la preservación de derechos que ostenta todo ente u órgano de naturaleza política cuya actividad se orienta a fines generales y debe respetar la legalidad en su sentido más amplio.

Pero no debemos olvidar el concepto de legitimación en la vía previa al amparo constitucional. Al respecto el art. 46.1 de la LOTC añadió otros requisitos a los exigidos por la CE en el art. 162.1.b. La expresión "interés legítimo" no aparece en la ley orgánica que concede legitimación activa en los procesos de amparo constitucional a la persona directamente afectada (supuesto del art. 42) y a quiénes hayan sido parte en el proceso judicial correspondiente (arts. 43 y 44 de la LOTC). La legitimación del Defensor del Pueblo y del Ministerio Fiscal no ha sufrido restricciones. La aparente limitación de la legitimación no suscitó debates a lo largo del "iter parlamentario" pues el objetivo primordial consiste en fijar un recurso en el cual fuera obligatorio agotar la vía ordinaria. Las situaciones más graves se plantean cuando al titular del interés legítimo se le exige haber sido parte en el proceso judicial correspondiente y las situaciones de indefensión se producen porque no existe un proceso "ad hoc" para la defensa de los derechos perturbados o en caso de existir no ha podido ser parte porque no gozaba de legitimación o ésta le ha sido denegada (art. 44 LOTC). Cabe también la posibilidad (art. 43 LOTC) de que el titular del interés legítimo pueda ver restringida su legitimación procesal porque en el marco de la jurisdicción contencioso-administrativa el concepto de interés directo, más restrictivo, excluya a los titulares de un interés legítimo. En cambio, la doctrina y la Jurisprudencia del TC mantienen que para ser parte en un recurso de amparo no es suficiente con haberlo sido en el proceso previo, ya que es requisito indispensable ser titular de un interés legitimo. La interpretación correcta de la legitimación acti- 
va obliga a entender que gozan de ella incluso terceros ajenos al proceso ordinario, partes o no en el proceso donde se produjo el agravio, aunque no se le haya facultado para recurrir frente a esa vulneración. La vía adecuada consiste en alegar la vulneración del art. 24.1 de la CE que constitucionaliza el derecho a la tutela judicial efectiva. La excepción que confirma la regla del criterio aperturista es el requisito de exigir haber sido parte en el proceso previo y el recurrente en amparo no lo fue debido a su inactividad o negligencia (GONZÁLEZ PÉREZ).

Ahondando en el criterio amplio de la legitimación activa el art. 24.1 de la CE reconoce el derecho a la tutela judicial efectiva a «todas las personas». Esta expresión plural ha sido entendida por la Jurisprudencia delTC como "el derecho de todos a la jurisdicción" que en cuanto derecho fundamental es «predicable de todos los sujetos juridicos". O sea, no sólo a los ciudadanos, sino también a los extranjeros y a toda persona natural o jurídica.

6. Otra preocupación latente en el proceso constituyente fue la de no convertir al recurso de amparo en una «supercasación». Por ello en el art. 44.1.b de la LOTC se prohíbe al TC «entrar a conocer» de los hechos que dieron lugar al litigio en el que se produjo la decisión judicial que se impugna. EITC, pues, debe aceptar los hechos probados $Y$ conocer sobre la aplicación del derecho. Pero, esto no basta para definir nuestro recurso en cuestión ya que debemos acudir al art. 55.1 de la LOTC; norma que otorga al Alto Tribunal la facultad de anular el acto lesivo y la facultad de restablecer al recurrente en la integridad de su derecho adoptando incluso las medidas necesarias para su conservación. Así las cosas, el recurso de amparo no puede ser considerado como un simple recurso de casación porque la función deITC no es la de casar la sentencia lesiva devolviendo al inferior el conocimiento del asunto, sino la de resolver por sí mismo, directamente, el litigio planteado. Pero, si no es un recurso de casación, tampoco es un recurso en interés de ley (RUBIO LLORENTE) cuyos efectos se proyectan hacia el futuro, aunque en algunos casos pueda presentar una estructura análoga a la de estos recursos. Se trata de una forma procesal próxima a la revisión tradicional y germánica destinada a corregir la aplicación del derecho en el caso concreto y por motivos intraprocesales. La interpretación de la norma no es su fin exclusivo aunque es consustancial a la tarea delTC. Como el amparo se configura frente a actos de poderes públicos, este recurso queda desligado de la posible inconstitucionalidad de la ley que regula los derechos y debe ser aplicada por el juez mientras esté vigente. Así el art. 55.2 de la LOTC contempla la inconstitucionalidad de la ley como una eventualidad, entre otras, de la violación de los derechos fundamentales; resultado de lo 
cual la sala que conoce del amparo elevará al Pleno la cuestión interna de inconstitucionalidad que permite que a través del recurso de amparo elTC juzgue no solo la aplicación de normas que en sí mismas o en la aplicación hecha por el juez son inconstitucionales, sino también las infracciones puras y simples de la legalidad vigente (FIGUERUELO).

A pesar de la buenas intenciones para distinguir entre la legalidad que le corresponde al juez ordinario y la constitucionalidad que es función del juez constitucional se encuentran serias dificultades para lograr esa separación. Hay problemas en fraccionar un ordenamiento considerado como algo único. El recurso de amparo es un verdadero recurso y no solo una vía subsidiaria para proteger algunos derechos fundamentales constitucionalmente reconocidos. La función jurisdiccional en este campo es ejercida por dos órganos distintos: el Poder Judicial y el Tribunal Constitucional. En esta relación el órgano supremo es el que controla la actuación del otro, es decir el TC, que se ocupa de analizar si la actuación del juez ordinario está de acuerdo con la Constitución (RUBIO LLORENTE).

7. La diferencia doctrinal entre amparo ordinario $y$ amparo constitucional ha surgido del contenido del art. $\mathbf{5 3 . 2}$ de la CE que al regular las garantías de los derechos fundamentales comprendidos entre los arts. 14 al $302 .^{\circ}$ de la norma suprema estableció que gozaran de una doble protección:

1. Tutela de los tribunales ordinarios a través de un procedimiento basado en los principios de preferencia y sumariedad $y$,

2. "En su caso», a través del recurso de amparo ante el Tribunal Constitucional.

El art. 165 de la CE remite a una ley orgánica que en sus arts. 41 al 58 desarrolla el "amparo constitucional" de forma no ajena al "amparo ordinario». Este recurso exige que el legislador dé cumplido desarrollo al contenido del art. 53.2 de la $C E$, cuestión que hasta la fecha no se ha realizado. Aquí se encuentran la mayor parte de los problemas que en la actualidad aquejan al Tribunal Constitucional.

Con carácter provisional la Ley 62/78, de 26 de diciembre, de Protección Jurisdiccional de los Derechos Fundamentales de la Persona, fue adaptada en sucesivas reformas para poder abarcar con sus vías judiciales el ámbito del objeto protegido por el recurso de amparo, regulado en el art. 43 de la LOTC (Gobierno y administración tanto de ámbito estatal como autonómico), en lo que a la vía ordinaria se refie- 
re. Quedaba sin resolver el caso de las violaciones causadas por actos del poder judicial, a lo que se dio respuesta en el art. 44 de la LOTC exigiendo alegar el derecho violado en cuanto hubiera lugar para ello y agotar todos los recursos utilizables dentro de la vía judicial. En el artículo 45 de la LOTC, se configuraba un recurso de amparo frente a actos violatorios del derecho a la objeción de conciencia, desarrollado ulteriormente por la LO $8 / 84$ de 26 de diciembre que derogó el precitado artículo de la LOTC. Ni este recurso, hoy vacío de contenido, ni el que contempla el art. 42 de la LOTC para impugnar actos sin valor de ley del poder legislativo, han ocasionado problemas al Alto Tribunal. La jurisprudencia, en ambos casos, es escasa y en el supuesto del art. 42 no se contempla como un remedio subsidiario.

Los problemas vienen de la mano del contenido disperso que las normas legislativas han ido dando a las distintas vías previas en función del poder público que causa la violación y del órgano judicial que debe resolver el caso. (RODRIGUEZ BEREIJO).

En el supuesto del art. 42 de la LOTC, observamos que la Ley Orgánica que regula la iniciativa legislativa popular (3/84, de 26 de marzo) en su art. 6, contempla un recurso de amparo ante el TC frente a los actos desestimatorios de una proposición de ley presentada ante la Mesa del Congreso.

Si nos fijamos en el "desarrollo" del art. 43 de la LOTC conviene que traigamos a colación la siguiente normativa:

- La Ley 62/78, de 26 de diciembre de PJDFP, modificada por la LO 1/92, de 21 de enero, que prevé un proceso especial en los órdenes civil, administrativo y penal para toda violación causada por actos de los poderes públicos o de los particulares en los derechos fundamentales objeto de protección en amparo. También la Ley $29 / 98$ de 13 de julio que regula la Jurisdicción Contencioso-Administrativa deroga expresamente los arts. 6 al 10 de la Ley $62 / 78$ y, con ello, se rompe el desarrollo unitario del art. 53.2 de la CE.

- La L.O. 9/83, de 15 de julio reguladora del derecho de reunión.

- La L.O. 1/82 de 5 de mayo (con sus correspondientes reformas) que regula el derecho al honor, a la intimidad personal y familiar y a la propia imagen.

- La Ley 5/84 de 26 de marzo que regula el derecho de Asilo y la condición de refugiado. 
- La L.O. 5/85, de 19 de junio, de Régimen Electoral General, que con el objeto de proteger el art. 23 de la CE establece una serie de recursos constitucionales del procedimiento electoral.

- La LO. 6/84, de 24 de mayo que regula el procedimiento de "Habeas Corpus" y tutela la libertad personal.

- La Ley del Proceso Laboral de 1995 que en sus arts. 175 a 182 establece un procedimiento de tramitación urgente y preferente de los derechos de libertad sindical.

En el ámbito del art. 44 de la LOTC, el amparo constitucional depende de la correcta aplicación de los procesos previos ante la jurisdicción ordinaria y su sistema de recursos. Urgen reformas en las leyes procesales para reforzar las posibilidades de autocontrol de la jurisdicción ordinaria y permitir la exigencia de instancias o recursos en la vía ordinaria para reparar las infracciones "in procedendo». A este fin obedece la reforma del art. 240 de la L.O. del Poder Judicial efectuada por la LO 5/97, de 4 de diciembre, dentro del denominado «incidente de nulidad de actuaciones". Se trata de un proceso autónomo contra sentencias firmes que cabe solo cuando se haya producido indefensión o el fallo sea incongruente. En este mismo sentido debe entenderse la Ley $1 / 2000$ de 7 de enero que pretende acomodar el proceso civil a las exigencias de la tutela efectiva proclamada en la Constitución, por lo que contiene abundantes normas referidas al amparo ordinario entre las que merece especial mención el «recurso extraordinario por infracción procesal» (arts. 468 al 476). Son competentes para su resolución las Salas de lo Civil y Penal de los Tribunales Superiores de Justicia de las CC.AA. Frente a sus resoluciones cabe un recurso ante el Tribunal Supremo en pro de la unificación de doctrina. Se trata de una fase previa más en el ámbito de la justicia ordinaria antes de acudir alTC. Del éxito de la regulación efectuada sólo el tiempo podrá darnos cuenta.

8. De la propia naturaleza jurídica de recurso de amparo y de los términos amplios y genéricos con los que el constituyente definió las garantías del proceso, así como de la generosa interpretación que de las mismas ha realizado el Tribunal Constitucional (art. 24.1 de la $\mathrm{CE}$, han provocado que gran número de decisiones judiciales hayan terminado siendo recurridas en amparo ante eITC originando un incremento continuo de demandas que pueden llegar a colapsar el funcionamiento del TC. Por todo ello el art. 24 de la CE está siempre en el punto de mira a la hora de resaltar los aspectos más problemáticos del recurso de amparo y las necesidades de reforma que la institución requiere (LAPUENTE ARAGO). 
La situación actual del recurso de amparo en España hace que un sector de la doctrina predique de esta garantía las mismas características que en su día predicara la doctrina alemana de la "Verfassungsbeschverde" o recurso de queja: se trata de un recurso «sin coste, sin esfuerzo y sin esperanza" (VON MÜNCH). La abundancia de recursos planteados sobrecarga de trabajo al Tribunal, impidiendo el normal desarrollo del resto de la funciones que le han sido encomendadas por la Constitución o las leyes orgánicas. No obstante, la práctica del Alto Tribunal cuando ha resuelto este tipo de recursos ha hecho que la Constitución se convierta para los españoles en una realidad viva y presente donde la libertad perturbada puede verse realizada. Pese a que nuestra normativa no contempla el "amparo frente a leyes", éste ha sido el instrumento que ha servido para invalidar algunas normas legales que atentaban contra alguno de los derechos amparables, sobre todo el derecho a la igualdad. Tampoco se contemplaba el amparo frente a particulares o poderes privados $y$, de forma indirecta, a través de la actuación del juez en cuanto poder público ha tenido entrada e nuestra jurisprudencia la teoría de la "Drittwirkung der Grundrechte».

También ha sido el recurso de amparo el que ha permitido que las prácticas forenses, algunas de ellas centenarias, fueran adaptadas a la Constitución, en la mayor parte de los casos obligando a una respetuosa observancia de las normas ya existentes antes que invalidando normas procesales incompatibles con la Constitución, aunque en algunos casos también se haya procedido a esto último. Estos logros se han conseguido con un coste no muy elevado de roces o malentendidos entre el Poder Judicial ordinario y el Tribunal Constitucional.

Por lo antes resaltado opinamos que el balance es positivo y lo mejor es dejar las cosas en su sitio y que sigan funcionando como hasta ahora lo han hecho. Pero, si hacemos caso a las voces de los alarmistas y pensamos que el estado de la cuestión es preocupante y puede acarrear el desprestigio del tribunal y del instituto del amparo será conveniente proceder a mejorar el funcionamiento del órgano y del recurso en cuestión. Es evidente el incremento constante del número de recursos. No surtió efectos la descafeinada reforma de la LOTC en 1988 (RUBIO LLORENTE), ni la simplificación del trámite de admisión, ni la reorganización de los métodos de trabajo, ni el incremento en el número de sentencias pronunciadas (CRUZVILLALÓN). Luego, si se ha llegado a un punto donde la doctrina constitucionalista (CRUZ VILLALÓN, PÉREZ-TREMPS, DIEZ-PICAZO...) se pronuncia por una reforma profunda y seria que descargue de trabajo al TC no pueden dejarse a un lado una serie de cautelas que todas las reformas que pue- 
dan plantearse deben observar a la hora de ponerse en práctica. Obedecen esas cautelas a la naturaleza de los derechos, al objeto protegido por el recurso en cuestión que constituyen el máximo nivel de protección dentro del ordenamiento jurídico, siendo los pilares básicos de nuestro sistema democrático.

Por ello debe respetarse el contenido esencial de los derechos que tutela el amparo y cualquier reforma no debe afectar a las condiciones del ejercicio de los mismos ni al nivel de tutela que constitucionalmente se le ha reconocido. No puede extrañar la opinión unánime de la doctrina cuando se pronuncia a favor de no tocar el marco constitucional del recurso de amparo a pesar de no estar afectado por el procedimiento agravado de reforma que regula el artículo 168 de la CE. Sí lo están casi todos los derechos objetos de protección en amparo (arts. 15 al 29 de la CE). Por lo que este procedimiento actúa como si se tratase de cláusulas de intangibilidad y prácticamente imposibilita "sacar" de dicho grupo al derecho a la tutela judicial efectiva que recoge el art. 24 de la Constitución.

Es mucho más fácil proceder a reformar la LOTC en lo referente a los procedimientos de amparo. Pero hasta la fecha ningún gobierno con mayoría suficiente se ha atrevido a hacer una reforma en profundidad de dicha norma. Quizás ha prevalecido el impacto sociológico que pueden tener estos temas ya que obligan a tener presenta que la función hipergarantista delTC ha creado un caldo de cultivo en la opinión pública que es difícil de cambiar. Cualquier modificación aparecerá como un recorte en las libertades públicas y supondrá costes políticos elevados. Una buena reforma debe estar consensuada por todas las fuerzas políticas y debe estar muy bien presentada a la opinión pública. Quizás por las dificultades planteadas todas las reformas efectuadas hasta la fecha han sido eventuales y de parcheo y no han entrado en el fondo del asunto.

Por todo ello debemos constatar que un amplio sector de la doctrina se pronunció por un desarrollo legal adecuado de las previsiones constitucionales referidas a la vía previa al amparo ante el TC. El procedimiento "preferente y sumario" previsto en el art. 53.2 de la CE ha tenido un desarrollo fragmentario ineficaz e incompleto. Se hace obligado facilitar la labor del juez en la aplicación de las leyes procesales lo cual obligaría al legislador a desarrollar medidas cautelares para proteger derechos sustantivos y modificar las normas procesales que mayores infracciones generan en el art. 24 de la CE. Esa modificación implicaría positivar las directrices interpretativas de las mismas sentadas por la jurisprudencia constitucional. 
Las propuestas de reforma más avanzadas apuestan por introducir en la LOTC la posibilidad de que este órgano constitucional pueda inadmitir las demandas de amparo por razones de oportunidad, seleccionado los casos de los que va a conocer por su relevancia práctica y conceptual. Se trataría de una especie de "Writ of certiorari», institución de gran calado en los sistema de "common law" pero sin antecedentes en nuestro derecho, ni en los sistemas continentales de raíz franco-germánica. Ello implicaría el reforzamiento de la dimensión objetiva del amparo y la potestad amplia de rechazo por elTC de aqueIlos recursos de amparo que no le interesen para reforzar la vertiente objetiva de concreción y desarrollo de los derechos individuales - aproximación al modelo estadounidense- (LÓPEZ PIETSCH). Este modelo reduce la dimensión subjetiva del amparo, menoscabando el derecho a la tutela efectiva que ha arraigado entre los ciudadanos y generaría inseguridad y pérdida de confianza en el sistema de protección de derechos. Creemos que los inconvenientes pueden superar a las ventajas porque si no se reforma la Constitución la vertiente subjetiva del recurso de amparo sigue estando presente en la norma suprema y esta garantía constitucional sigue siendo un recurso "al que se tiene derecho" aunque no en virtud del derecho a la tutela judicial efectiva. Por ello no puede ser negado, como el «writ of certiorari», sino solo inadmitido, es decir que se le rechaza en virtud de causas previamente establecidas en la ley (RUBIO LLORENTE).

Después de tantos años de funcionamiento del TC concluimos que la institución ha conseguido arraigar en parte, gracias a las funciones que el constituyente le encomendó. De entre esas competencias destaca el recurso de amparo constitucional. Esto es debido a su objeto: protección de derechos y libertades de los ciudadanos frente a violaciones causadas en la esfera de la libertad personal por actos de los poderes públicos, y a su función: otorgar justicia en el caso concreto y contribuir al desarrollo objetivo de los contenidos constitucionales. La amplitud del espectro de posibilidades de actuación concreta del recurso de amparo han hecho que la Constitución Española de 1978 , tal y como ha sido aplicada hasta ahora, sería reconocible sin la Cuestión de Inconstitucionalidad, y sin el Recurso de Inconstitucionalidad, pero no sería la misma norma de no haber existido el Recurso de Amparo (CRUZ VILLALÓN). 


\section{BIBLIOGRAFÍA DE REFERENCIA}

AGUIAR DE LUOUE: Los derechos fundamentales en las relaciones entre privados. Estado de la cuestión, Actualidad Jurídica, X, 1981.

BAssols ComA, M.: La jurisprudencia del Tribunal de Garantías Constitucionales, CEC, Madrid, 1981.

BILBAo UBILlos, J. M.: Los derechos fundamentales en la frontera entre lo público y lo privado, McGraw-Hill, Madrid, 1997.

BöCKENFÖRDE, E. W.: Estudios sobre el Estado de Derecho y la Democracia, Ed. Trotta, Madrid, 2000.

- Escritos sobre derechos fundamentales, Nomos Verlagsgessellschaft, Baden-Baden, 1993.

Borrajo INIESTA, l.: "Amparo frente a las leyes", RAP, n. ${ }^{\circ} 98$, Madrid, 1982.

- El amparo judicial: La innecesariedad e inconveniencia de encauzarlo mediante procedimientos específicos y de confiárselo a órganos especializados, Consejo General del Poder Judicial, Madrid, 1994.

Bustos GISBERT, R.: “¿Está agotado el modelo de recurso de amparo diseñado en la CE?», en Teoría y realidad constitucional, n. ${ }^{\circ} 4$. UNED, 1999.

CANO MATA: «EI recurso de amparo (Doctrina del Tribunal Constitucional). Edersa. Madrid, 1983.

CAPPelletti, M.: La giurisdizione costituzionale delle libertá, Giuffré, Milán, 1971.

CASCAJo CASTRO, J. I.: "Los derechos invocables en el recurso de amparo", en M. A. García Herrera, El constitucionalismo en la crisis del Estado Social, Universidad del País Vasco, Bilbao, 1997.

CORDón MoReno, F: Consideraciones sobre la legitimación activa en el proceso de amparo constitucional, La Ley, 1984.

Cruz Villalón, P.: «El juez y el legislador». Primera ponencia sobre el recurso de amparo en Los procesos Constitucionales, CEC, Madrid, 1992.

- "Sobre el amparo», REDC, n. ${ }^{\circ} 41$, Madrid, 1994.

DIEZ-PICAZO JIMÉNEZ, I.: ElTribunal Constitucional, jurisdicción ordinaria y derechos fundamentales, McGraw-Hill, Madrid, 1996. 
Díez-PICAZo JIMÉNEZ, L. M.: «Dificultades prácticas y significado constitucional del recurso de amparo", REDC, n. ${ }^{\circ}$ 40, Madrid, 1994.

EmBid IRUjo, A.: «El Tribunal Constitucional y la protección de las libertades públicas en el ámbito privadon. Vol. I de la obra colectiva EI Tribunal Constitucional, IEF, Madrid, 1981.

Figueruelo BurriezA, A.: El derecho a la tutela judicial efectiva, Tecnos, Madrid, 1990.

- «Algunos problemas que suscita la autocuestión de inconstitucionalidad (art. 55.2 de la LOTC)", REDC, n. ${ }^{\circ} 21$, Madrid, 1987.

- Los derechos fundamentales en el Estado Social y su eficacia en las relaciones privadas, Universidad Externado de Colombia, 1996.

- El recurso de amparo: Estado de la cuestión, Biblioteca Nueva, Madrid, 2001.

FIX Zamudio, H: «El derecho de amparo en México y en España. Su influencia recíproca», $R E P, \mathrm{n} .{ }^{\circ} 7$, Madrid, 1979.

- Veinticinco años de evolución de la justicia constitucional, 19401965, UNAM, México, 1968.

Friginal y Fernández VilLaVERDE, L.: La protección de los derechos fundamentales en el ordenamiento español, Montecorvo, S.A., Madrid, 1981.

GaRCíA RocA, J.: "Cuestionario sobre la reforma de la LOTC", en Teoría $y$ realidad constitucional, monográfico sobre "El Tribunal Constitucional", Madrid, 1999.

García RuIz, J. L.: El recurso de amparo, Editora Nacional, Madrid, 1980.

GaRCIA TORRES, J., Y JIMÉNEZ BLANCO, A.: Derechos fundamentales y relaciones entre particulares, Ed. Civitas, Madrid, 1986.

González Pérez, J.: El derecho a la tutela jurisdiccional. Civitas, S.A., Madrid, 1984.

González Trevijano, P: «La legitimación en el recurso de amparo. Los interesados legítimos", Revista de Derecho Público, n. ${ }^{\circ} 98$, Madrid, 1985.

JiMÉNEZ CAMPO, J.: «Artículo 53, protección de los derechos fundamentales", en Ó. Alzaga, Comentarios a la CE de 1978, tomo IV, Madrid, Edersa, 1996.

KeLSEN, H.: Teoría General del Derecho y del Estado, México, UNAM, 1979. 
- La giustizia costituzionale, Giuffré, Milán, 1981.

LAPUENTE ARAgo, R.: "Las dificultades el recurso de amparo en cifras", Anuario de Derecho Constitucional y Parlamentario, n. ${ }^{\circ}$ 2, 1990.

LóPEZ PIETSCH, P.: "Objetivar el recurso de amparo: las recomendaciones de la Comisión Benda y el debate españoln, REDC, n. ${ }^{\circ} 53$, Madrid, 1998.

MÜNCH (von), l.: «El recurso de amparo constitucional como instrumento jurídico y político en la República Federal en Alemania», REP, n. ${ }^{\circ}$ 7, Madrid, 1979.

Osuna PatiNo, N.: Tutela y amparo: Objeto protegido, Universidad Externado de Colombia, 1998.

PABÓN DE ACUÑA: "La llamada "Drittwirkung" de los derechos fundamentales», vol. III de la obra colectiva EI Poder Judicial, IEF, Madrid, 1983.

Pérez Tremps, P.: “El recurso de amparo constitucional. Aspectos problemáticos». Segunda ponencia sobre "El recurso de amparo", en Los Procesos Constitucionales, CEC, Madrid, 1992.

Poyal Costa, A.: "La eficacia de los derechos humanos frente a terceros", Revista de Derecho Político, n. ${ }^{\circ}$ 34, UNED, Madrid, 1991.

QUADRA-SALCEDO, T.: El recurso de amparo y los derechos fundamentales en las relaciones entre particulares, Civitas, Madrid, 1981.

REVEnGA SÁNCHEZ, M.: «Las paradojas del recurso de amparo tras la primera década de jurisprudencia constitucional", REDC, $n .^{\circ} 41$, Madrid, 1994.

ReYes OCHOA, R.: La defensa constitucional, Ed. Espasa-Calpe, Madrid, 1934.

Rodríguez BereiJo, A.: "Cuestionario sobre la reforma de la LOTC", en Teoría y realidad constitucional, n. ${ }^{\circ}$ 4, Madrid, 1999.

RUBIO LLORENTE, F.: "Seis tesis sobre la jurisdicción constitucional en España», REDC, n. ${ }^{35}$, Madrid, 1992.

- El trámite de admisión del recurso de amparo en "La forma del poder", CEC, Madrid, 1993.

- "El recurso de amparo», en Estudios sobre la jurisdicción constitucional, McGraw-Hill, Madrid, 1998.

Ruipérez Alamillo, J.: La Constitución Europea y la teoría del poder constituyente, Ed. Biblioteca Nueva, Madrid, 2000. 
Ruiz Lapeña, R. M.: El Tribunal de Garantías de la Segunda República Española, Ed. Bosch, Barcelona, 1982.

- El recurso de amparo durante la Segunda República Española, Ed. REP, n. ${ }^{\circ}$, Madrid, 1979.

SOlÉ TURA Y AJA: Constituciones y períodos constituyentes en España (1808-1936),. Siglo XXI Editores, Madrid, 1983.

TOMÁs VILLARRoYa, J.: Breve historia del constitucionalismo español, . CEC, Madrid, 1982.

VARELA DiAz, S.: "La idea de deber constitucional», $R E D C, n .^{\circ} 4$, Madrid, 1982.

VEGA GaRcía, P. de: "La crisis de los derechos fundamentales en el Estado Social", en Derecho y economía en el Estado Social, Tecnos, Madrid, 1988.

- «Mundialización y derecho constitucional: La crisis del principio democrático en el constitucionalismo actual», REP, n. ${ }^{\circ} 100$, Madrid, 1998.

WALH, R., y WIELAND, J.: «La jurisdicción constitucional como bien escaso. El acceso al BVG», REDC, n. ${ }^{\circ}$ 51, Madrid, 1997. 